\title{
Familial Hemophagocytic Lymphohistiocytosis Type 3
}

\author{
Yue $\mathrm{Du}^{1} \cdot \mathrm{Li} \mathrm{Li}^{1} \cdot$ Xiao Ying Wang ${ }^{1} \cdot$ Liang Chen $^{1} \cdot$ Sheng Hua Jia ${ }^{1} \cdot$ Rong $\mathrm{Mi}^{1}$
}

Received: 18 March 2020 / Accepted: 3 April 2020 / Published online: 6 May 2020

(C) Dr. K C Chaudhuri Foundation 2020

To the Editor: A newborn boy was admitted to a local hospital with fever and splenomegaly. He was the mother's second pregnancy and first birth, born after an uncomplicated pregnancy, with healthy and non-consanguineous parents. The first pregnancy was voluntary abortion. Prenatal ultrasound revealed normal fetal growth and development ever before, but at $393 / 7 \mathrm{wk}$, it revealed splenomegaly, ascites and fetal cerebral ventriculomegaly. The next day, he was delivered by cesarean section with a birth weight of $3550 \mathrm{~g}$ and a length of $50 \mathrm{~cm}$, additionally the apgar scores was 10 points. $\mathrm{He}$ showed no dysmorphic features. The routine blood test showed WBC $8.1 \times 10^{9} / \mathrm{L}$, neutrophils $0.92 \times 10^{9} / \mathrm{L}$, hemoglobin $120 \mathrm{~g} / \mathrm{L}$, platelets $33 \times 10^{9} / \mathrm{L}$, CRP $21.1 \mathrm{mg} / \mathrm{L}$, atypical lymphocyte $20 \%$; normal liver enzymes, and ultrasound showed splenomegaly and cholestasis. He was diagnosed with infection and treated with kinds of antibiotics and blood products, but the disorder still deteriorated.

After $18 \mathrm{~d}$, he was admitted to our department as his fourth hospital. Physical examination revealed fever, tachypnea, petechiae, lymphadenopathy, hepatosplenomegaly and abdominal distension. Laboratory examination revealed anemia, neutropenia, thrombopenia, elevated liver enzymes, cholestasis, high ferritin, high triglyceride and low fibrinogen. The CD107a excitation experiment showed that the degranulation function of $\mathrm{NK}$ cell is decreased $(\triangle \mathrm{CD} 107 \mathrm{a}<5 \%)$. Inflammatory cytokines were increased, especially sCD25 (29135 pg/ml). NK cell count were $2 \%$, NK cell's activity counts were $20.85 \%$. The bone marrow aspirates showed hemophagocytosis. The chest CT showed lung exudation, a number of enlarged and significantly enhanced bilateral axillary lymph nodes. Thus he was diagnosed with Hemophagocytic lymphohistiocytosis (HLH), and treated

Rong Mi

mr85695601@sina.com

1 Department of Pediatrics, Newborn Medicine, Children's Hospital, Capital Institute of Pediatrics, 2\# Yabao Road, Beijing, China with additional dexamethasone and cyclosporine according to the HLH 2004 protocol.

On the 30th day of life, the genetic analysis from his peripheral blood, demonstrated the compound heterozygous mutations of $U N C 13 D$ gene: c. $118-308 \mathrm{C}>\mathrm{T}$ in intron 1 which was pathogenetic and inherited from his father; the other mutation c.3002 T > C, in exon 31, p.L1001P was predicted to be probably pathogenic using 2 different protein programs (PolyPhen, SIFT) and inherited from his mother. Then his diagnosis was corrected as Familial hemophagocytic lymphohistiocytosis type 3 (FHL3). But the hematopoietic stem cell transplantation (HSCT) was refused, and he died of the infection at $52 \mathrm{~d}$ of age [1-3].

\section{Compliance with Ethical Standards}

Conflict of Interest None.

\section{References}

1. Meeths M, Chiang SC, Wood SM, et al. Familial hemophagocytic lymphohistiocytosis type 3 (FHL3) caused by deep intronic mutation and inversion in UNC13D. Blood. 2011;118:5783-93.

2. Henter JI, Horne A, Arico M, et al. HLH-2004: diagnostic and therapeutic guidelines for hemophagocytic lymphohistiocytosis. Pediatr Blood Cancer. 2007;48:124-31.

3. Sieni E, Cetica V, Santoro A, et al. Genotype-phenotype study of familial haemophagocytic lymphohistiocytosis type 3. J Med Genet. 2011;48:343-52.

Publisher's Note Springer Nature remains neutral with regard to jurisdictional claims in published maps and institutional affiliations. 